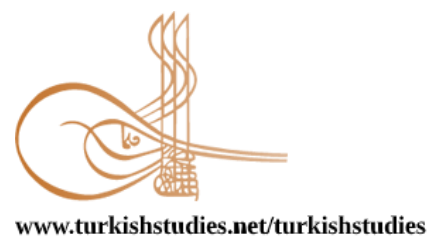

Turkish Studies

\title{
Turizmde "Sosyal Mesafe” Mümkün Mü? Kamp ve Karavan Turizmi Bağlamında Bir Değerlendirme
}

\author{
Is "Social Distancing" Possible in Tourism: An Evaluation in the Context of Camping and Caravan \\ Tourism
}

\author{
Ümit Şengel $^{*}$ - Koray Genç ${ }^{* *}$ - Merve Işkın ${ }^{* * *}$ - Şevki Ulema ${ }^{* * * *}$ - İsmail Uzut ${ }^{* * * * *}$
}

\begin{abstract}
The COVID-19 pandemic originated in Wuhan, China and has affected the whole world by the first quarter of 2020. Except of some minor assistance during the pandemic process, most countries acted alone and applied their own methods in combating the pandemic. After the period in which new cases of the virus have fallen, countries have started a process called the "new normal" with rules such as social distance, mask and hygiene. In some areas of life there are concerns about the applicability of social distance in particular. In this study, it is aimed to examine the applicability of the" social distancing" rule conceptually in the context of camping and caravan tourism in tourism activities dominated by human relations based on close contact. Camping and caravan tourism is an important alternative form of tourism to be made by paying attention to the "social distancing" rule to prevent the spread of the COVID-19 pandemic. In this tourism type, accommodation activities are limited with a small number of families and friends. In addition, people themselves play an active role in meeting basic needs. All this, increases the demand for camping and
\end{abstract}

\footnotetext{
* Dr., Sakarya Uygulamalı Bilimler Üniversitesi, Turizm Fakültesi, Turizm Rehberliği Dr.., Sakarya University of Applied Sciences, Faculty of Tourism, Department of Tour Guide Training ORCID 0000-0003-1284-836X

umitsengel@gmail.com

** Dr, Bolu Abant İzzet Baysal Üniversitesi, Mudurnu Süreyya Astarcı Meslek Yüksekokulu, Otel Lokanta ve İkram Hizmetleri

Dr., Bolu Abant Izzet Baysal University, Vocational School, Tourism and Hotel Operating

ORCID 0000-0001-5477-4683

koraygenc@yahoo.com

**** Dr., İstanbul Esenyurt Üniversitesi, Meslek Yüksekokulu, Otel Lokanta ve İkram Hizmetleri

Dr., Istanbul Esenyurt University, Vocational School, Tourism and Hotel Operating

ORCID 0000-0002-4748-0422

merveiskin@esenyurt.edu.tr

**** Doç. Dr., Sakarya Uygulamalı Bilimler Üniversitesi, Turizm Fakültesi, Gastronomi ve Mutfak Sanatları

Assoc. Prof. Dr., Sakarya University of Applied Sciences, Faculty of Tourism, Department of Gastronomy and Culinary Arts

ORCID 0000-0002-5874-8797

ulema@subu.edu.tr

****** Doktora Öğrencisi, Sakarya Uygulamalı Bilimler Üniversitesi, Lisansüstü Eğitim Enstitüsü

PhD Student., Sakarya University of Applied Sciences, Graduate Education Institute

ORCID 0000-0001-6227-7249

ismailuzut@maltepe.edu.tr

Cite as/ Atıf: Şengel, Ü., Genç, K., Işkın, M., Ulema, Ş. \& Uzut, İ. (2020). Turizmde "sosyal mesafe" mümkün mü?

Kamp ve karavan turizmi bağlamında bir değerlendirme. Turkish Studies, 15(4), 1429-1441. https://dx.doi.org/10.7827/TurkishStudies.44177

Received/Geliș: 12 June/Haziran 2020

Accepted/Kabul: 30 August/Ağustos 2020

Copyright (C) MDE, Turkey

Checked by plagiarism software

Published/Yayın: 30 August/Ağustos 2020

CC BY-NC 4.0
} 
caravan tourism as it instil confidence a sense of trust in people. This situation is always on the agenda of both national and international media tools. Therefore, travel companies are developing alternative products to respond to this new demand. Similarly, while the container areas have been redesigned according to the new rules, caravan companies have started to react according to the new demand.

Structred Abstract: In this study, it is aimed to examine the applicability of the "social distancing" rule conceptually in the context of camping and caravan tourism in tourism activities dominated by human relations based on close contact. Camping and caravan tourism has gained importance as an alternative accommodation concept after the epidemic due to some reasons such as applying social distance rules more comfortably, providing the opportunity to rest in a wide and spacious environment and meeting the basic needs of the persons themselves. Due to the fact that tourists stay away from engaging in crowded tourism activities due to safety concerns (Chen et al., 2004) appears to will increase interest in alternative tourism varieties such as camping and caravans. Because, tourists who care about their personal safety (Hall ve diğerleri, 2003) cancel their reservations or plans for traditional accommodation (hotels, resorts etc.), which provide shelter for many people at the same time in case of risk. It is thought that this study will contribute to the literature in terms of providing an alternative for tourists concerned about safety due to the COVID-19 outbreak and leading academic studies on the impact of the pandemic.

Begin with the emphasis on "social distancing", Tourism after COVID-19 prefers to return to more nature, gains time to slow down, and deals with international travel restrictions and more domestic travels due to the numerous limitations of lifestyle. After the pandemic, people will participate in tourism activities again, but the preferences in these activities seem to concentrate on preferences that are more suitable for "social distance". In this context, it is thought that the phenomenon called "slow tourism" will come to the fore as a preferable holiday choice (Travelzoo, 2020; Benjamin ve diğerleri, 2020).

In the normalization process after the pandemic, accommodation enterprises; It can be predicted that they will go above-normal price practices due to late season opening, inability to work at full capacity and increases in cost items due to measures. The Association of Turkish travel agents gave an opinion in this direction, and this year more people prefer alternative holidays, boutique hotels and hostels to be more preferred, a family presented a small pension predictions like that even close. However, it is stated that prices may be higher than before according to the possibility of hotels not working at full capacity (https://www.turizmguncel.com/haber/acik-bufeler-kalkacak-maske-zorunlu-olacak, 2020). Therefore, although there is an increase in caravan prices depending on demand, the fact that tent accommodation in campsites is cheaper than in regular accommodation can also be considered as an attractive factor for preference. Brooker and Joppe (2013:1) described Camp accommodation as a low-cost tourism niche, considering it in different segments, from luxury facilities to camping facilities to glamping facilities. So much so that in their research, Shalk et al (2018: 138), their motivation for participating in tented camping activity is 'affordability of price'. The report by a UK-based Sunday research firm also highlighted the increasing orientation to camping and caravan tourism in times of rising unemployment and economic decline (Mintel, 2013).

COVID-19, which affects the whole world, affects societies from different perspectives. First, it affected countries in the macro sense and firms and individuals in the micro sense in the economic, social and psychological sense. In fact, each of these interconnected elements has been negatively affected by this pandemic process. Thus, the negative effects of COVID-19 were further increased by the interplay of different economic units. As a matter of fact, tourism-themed cities have become ghost cities during this pandemic (Haywood, 2020). With the social distance slogan, COVID-19 aims to reduce the effects of the epidemic on the tourism industry and revitalize these ghost cities with tourism. So, is "social distancing" possible in tourism?

Tourism activities based on friendly and warm human relationships seem to gain a different identity due to the COVID-19 pandemic. The negative psychological effects of the pandemic on tourists have led tourists to alternative sources of demand and supply where they can do tourist activities without being affected by the outbreak. In terms of supply, it is expected that there will be an orientation especially to alternative types of tourism based on nature. Highland tourism, farm tourism, camp tourism, caravan tourism etc. it is thought that there will be an orientation to the types of Tourism compatible with nature. Zhu and Deng (2020) in their empirical research found that Chinese people prefer nature-based tourism. The research highlights that people prefer rural tourism to avoid risk. For this reason, measures should be taken in rural

Turkish Studies, 15(4) 
areas related to the outbreak. In addition, cultural tours in crowded cities, gambling tourism, such as human interaction intensive types of Tourism (Wong, 2020) and shopping tourism in crowded environments are thought to be adversely affected by the pandemic. There are also serious concerns about sea, sand and suncentric mass tourism. Because there are assessments of the risk of transmission of the virus by sea or pool waters, but there are no definitive investigations. Although there are a number of studies on "social distance" rules on beaches, it is necessary to state that there are some risks associated with achieving success as observed from different beaches around the world.

Another important aspect that tourism demand will react differently from normal due to the pandemic is the choice of accommodation. Because during the stay large crowds may stay in the same environment for a long time. There are serious concerns about the applicability of "social distance" rules, especially in large accommodation establishments such as hotels, resorts, and holiday complexes. In this sense, the risk is even higher in all-inclusive system-operated accommodation facilities in holiday zones. Because in such facilities, meals are common for all repast and services are provided with the help of open buffets. This can present great risks, especially with regard to hygiene and distance. Changing this concept may pose problems with claimability. Because tourists prefer this concept they buy all the services in a package At Reasonable Prices. Instead of hostel, camp, caravan, villa etc. it can be said that there is a significant increase in demand for accommodation preferences and that the situation will continue this way for some time in the future.

From the perspective of supply and demand, after the COVID-19 process, camping and caravan tourism comes to the fore as an alternative type of Tourism and type of accommodation to be preferred due to its compliance with the "social distance" rules. This type of Tourism and accommodation includes significant opportunities to adjust the physical distance (McCartney, 2020), which is one of the most important elements of social distance. In addition, basic needs, especially food and beverage services, are met directly by tourists. Thus, risk is reduced in this type of accommodation, a sense of confidence is developed and psychological relief is provided (Brooker and Joppe, 2013). Developments related to Caravan sales and applications and preparations of campsites in the process also support this situation.

The major important limitation of this research is that the study is based on a conceptual thinning. Because it may be useful to look at the course of developments in the summer season in order to carry out empirical studies on the subject. Applied research measuring tourist behaviour in the context of alternative tourism and accommodation preferences can be carried out in future times according to realized demand.

Keywords: Tourism, COVID-19, Epidemic Disease, Accommodation Services, Camping and Caravan Tourism, Social Distancing

Öz: COVID-19 pandemisi Çin'in Wuhan kentinde ortaya çıkmış ve 2020 yılının ilk çeyreği itibariyle bütün dünyayı etkisi altına almıştır. Pandemi sürecinde bazı küçük yardımlaşmaların dışında çoğu ülke tek başına hareket etmiş ve pandemiyle mücadelede kendi yöntemlerini uygulamıştır. Pik noktası olarak ifade edilen ve virüse yakalanan yeni vakaların düşüşe geçtiği dönemden sonra ülkeler sosyal mesafe, maske ve hijyen gibi kurallarla "yeni normal" diye tabir ettikleri bir süreci başlatmışlardır. Hayatın bazı alanlarında özellikle sosyal mesafenin uygulanabilirliğiyle ilgili endişeler söz konusudur. Bu çalışmada önemli oranda yakın temasa dayanan insan ilişkilerinin hâkim olduğu turizm faaliyetlerinde "sosyal mesafe" kuralının uygulanabilirliğinin kamp ve karavan turizmi bağlamında kavramsal olarak incelenmesi amaçlanmaktadır. Kamp ve karavan turizmi COVID-19 pandemisinin yayılmasını önlemek için "sosyal mesafe" kuralına dikkat edilerek yapılacak önemli bir alternatif turizm çeşididir. Bu turizm çeşidinde konaklama faaliyetleri az sayıda kişi ve aile veya arkadaş çevresiyle sınırlı kalmaktadır. Ayrıca temel ihtiyaçların giderilmesinde kişilerin kendisi aktif rol oynamaktadır. Bu durum güven duygusunun gelişmesine bağlı olarak kamp ve karavan turizmine olan talebi artırmaktadır. Bu durum hem ulusal hem de uluslararası medya araçların sürekli gündem olmaktadır. Dolayısıyla seyahat firmaları bu yeni talebeb cevap verebilmek için alternatif ürünler geliştirmektedir. Benzer şekilde özellikle kapm bölgeleri yeni kurallara göre yeniden dizayn edilirken, Karavan şirketleri de yeni talebe göre reaksiyon göstemeye başlamıştır.

Anahtar Kelimeler: Turizm, COVID-19, Salgın Hastalık, Konaklama Hizmetleri, Kamp ve Karavan Turizmi, Sosyal Mesafe 


\section{Giriş}

Turizm endüstrisi küreselleşmenin de etkisiyle günden güne büyümektedir. Bu büyüme 21 . yüzyılda büyük bir ivme kazanmıştır (Raymond ve Brown, 2007; Tang ve Abosedra, 2012; Fahimi ve diğerleri, 2018). Bu büyüme uluslararası turizm istatistiklerine de yansımaktadır. Uluslararası turist varışları 2018'de 1,4 milyar seviyelerindedir. Bu sayısal büyüme turizm endüstrisinin ekonomik gücünü de artırmıştır. Aynı şekilde 2018 yılında turizm, toplam dünya ihracatın \% 7'sini, dünya hizmetler ihracatının ise \%29'unu oluşturmaktadır (UNWTO, 2019). 2019 yılında uluslararası varışlar 1,462 milyar kişidir. İhracattaki paylar ise 2018 ile aynı seviyede kalmıştır (UNWTO, 2020). Bu büyümede toplumların refah düzeyine bağlı olarak bireylerin harcanabilir gelir ve boş zamanlarının artmasının oldukça önemli bir payı vardır (Lickorish ve diğerleri, 1997). $\mathrm{Bu}$ iyimser tablonun yanında, turizm dinamik yapısı nedeniyle dış olaylardan çok hızlı bir şekilde etkilenebilecek bir yapıya sahiptir (Gamble, 1992; Lee ve Harrald, 1999).

Turizmdeki dinamik yapıyı körükleyen ve yaşanan herhangi bir olumsuzluğun turizme olan etkilerini derinleştiren en önemli unsurların başında küreselleşme gelmektedir. Özellikle küreselleşmenin bir unsuru olarak gelişen ulaştırma ve iletişim teknolojileri meydana gelen krizlerin etkilerinde zaman ve mekan gibi unsurlara bağlılı̆̆ en aza indirmektedir. Bu kapsamda dünyanın herhangi bir yerinde meydana gelen bir olayın etkileri kısa bir zamanda uzak bir turistik destinasyonu etkileyebilir hale gelmektedir (Buhalis ve Law, 2008; Paraskevas ve diğerleri, 2013; Del Chiappa ve Baggio, 2015).

Turizm endüstrisini etkileyen farklı karakterdeki krizlerin olduğu bilinmektedir. $\mathrm{Bu}$ krizlerin başında ekonomik (Pambudi ve diğerleri, 2009; Stylidis ve Terzidou, 2014), politik veya diplomatik krizler (Hall ve O'Sullivan, 1996; Gilss, 2008; Hall, 2010 ), deprem, kasirga ve sel gibi doğal afetlerden kaynaklı krizler (Tse, 2006; Erol, 2010; Walters ve diğerleri, 2016), savaş ve terör (Smith, 1998; Thompson, 2011) gibi krizler gelmektedir. Bu krizlerin tamamının mahiyeti ve etkisi toplumlara ve iş kollarına göre değişkenlik gösterebilmektedir. Bunların turizm endüstrisinde özellikle talebi daraltıcı etkileri olduğu söylenebilir.

Turizm endüstrisini etkileyen diğer bir önemli kriz türü sağlık krizleridir. Bu kapsamda seyahatleri kısitlaması nedeniyle salgın hastalıklar turizm talebinde bir daralmaya neden olmaktadır. Bu hastalıkların turizme etkileriyle ilgili yapılan akademik çalışmalar da söz konusudur (Scott and Laws, 2005). Örneğin 2001 yılında İngiltere'de ortaya çıkan ayak ve ağız hastalığı salgınının temas ve solunum yoluyla yayılması nedeniyle turizm talebinde daralmaya neden olarak turizm endüstrisini olumsuz etkilediği bilinmektedir. Turizm talebinde daralmaya neden olan bir diğer önemli salgın, 2002 başında bazı Asya ülkelerinde ortaya çıkan SARS (şiddetli akut solunum sendromu) salgınıdır (Pine ve McKercher, 2004; Kuo ve diğerleri, 2008; McAleer ve diğerleri, 2010). Turizmde daralmaya sebep olan bir diğer salgın krizi 2009 yılında ABD'de Domuz gribidir. (Haque ve Haque, 2018). Turizm endüstrisini derin şekilde etkileyen bir diğer önemli salgın kuş gribidir. Özellikle konaklama sektöründe etkileri önemli şekilde hissedilmiştir. Salgın nedeniyle bazı konaklama işletmeleri iflas etmiştir. Talepteki daralmanın sebebi ise turistlerin sahip oldukları güvenlik endişesidir (Page ve diğerleri, 2006). 2013 yılında ortaya çıkan Gine/Afrika kökenli Ebola salgını da talep ve arz bağlamında turizm endüstrisini etkilemiştir (Kongoley, 2015; Mizrachi ve Fuchs, 2016).

2020 yılının ilk çeyreğinde bütün dünyayı büyük bir krizin içine iten bir salgın hastalık yayılmaya başlamıştır. İlk olarak Aralık 2019'da Çin'in Wuhan şehrinde görülen (Gralinski ve Menachery, 2020) COVID-19 olarak isimlendirilen küresel salgın giderek yayılmış ve tüm dünyada küresel bir sağlık sorunu haline gelmiştir (Munster vd, 2020; Menachery ve diğerleri, 2020). COVID-19'un ortaya çıkışıyla ilgili farklı varsayımlar bulunmakta (Perlman, 2020; Chu ve diğerleri, 2020) ve virüsün kökeniyle ilgili (Wang ve diğerleri, 2020; Backer ve diğerleri., 2020) çalışmalar yapılmaktadır. Bu teknik bilgilerden ziyade salgınla ilgili iki geçek COVID-19'un hayatın birçok alanında etkiler bırakmasına neden olmaktadır. Birincisi virüsün sahip olduğu 
yayılma hızı (Chu ve diğerleri, 2020:1), diğeri ise Dünya Sağlık Örgütü tarafindan bütün dünyayı etkilemesi nedeniyle salgını pandemi olarak ilan etmesidir (McCartney, 2020). Yaşanan gelişmeler uluslararası ve ulusal düzeyde insan haraketliliğini durma noktasına getirmiştir.

$\mathrm{Bu}$ çalışmada salgının etkilerinin azalmasından sonra ülkelerin uyguladığı sosyal mesafe kuralının turizm endüstrisindeki uygulanabilirliğinin, kamp ve karavan turizmi bağlamında kavramsal düzeyde tartışılması amaçlanmaktadır. Kamp ve karavan turizminde sosyal mesafe kurallarının daha rahat uygulanabilmesi, geniş ve ferah bir ortamda dinlenme imkanı sağlaması ve kişilerin beslenme başta olmak üzere temel ihtiyaçlarını kendilerinin karşılaması gibi bazı sebepler nedeniyle bu turizm çeșidi salgın sonrası alternatif bir konaklama konsepti olarak önem kazanmaktadır. Turistlerin güvenlik endișeleri nedeniyle kalabalık turizm faaliyetlerinde bulunmaktan uzak duruyor olması (Chen ve diğerleri, 2004) kamp ve karavan gibi alternatif turizm çeşitlerine olan ilgiyi arttıracak gibi görünmektedir. Zira, kişisel güvenliğine önem veren turistler (Hall ve diğerleri, 2003) risk durumunda aynı anda çok fazla kişiye barınma imkanı sağlayan geleneksel konaklama (otel, tatil köyü vb.) çeşitlerine yönelik rezervasyonlarını veya planlarını iptal etmektedir. Bu çalışmanın COVID-19 salgını nedeniyle güvenlik endişesi taşıyan turistler için bir alternatif sunması ve pandeminin etkileriyle ilgili alanda yapılacak akademik çalışmalara öncülük etmesi bakımından literatüre katkı sağlayacağı düşünülmektedir.

\section{COVID-19 Pandemisinin Turizme Yansımaları}

Uluslararası insan hareketliliği Çin'de ortaya çıkan COVID-19'un diğer ülkelere yayılmasını neden olmuştur. Bu durum turizm ile pandeminin yayılımı arasındaki etkileşimin en belirgin yansımasıdır. $\mathrm{Bu}$ insan hareketliliğinin pandeminin yayılmasına aracılık etmesi nedeniyle çoğu ülke vizeleri askıya alarak hastalığın yayılmasını önlemek için katı seyahat yasakları uygulama girişimlerinde bulunmuştur. Bütün bunlar turizme bağımlı turistik destinasyonların ciddi ekonomik problemlerle karşı karşıya kalmalarına neden olmaktadır (Wen, ve diğerleri, 2020)

COVID-19 dünyada birçok açıdan hayatı durdurma noktasına getirmiştir. Bu etkilerin en yoğun hissedildiği alanların başında ise turizm gelmektedir. Çin'de başlayan salgın doğal olarak ilk etapta Çin'deki turizm faaliyetlerini ve Çin pazarından yoğun talep alan destinasyonları etkilemiştir. Örneğin; 23-26 Ocak 2020 tarihleri arasındaki 3 günlük dönemde Çin otel piyasası, yıllık bazda \% 71'lik bir düşüşle karşılaşmıştır (Baker, 2020). Ancak virüsün yaygınlaşması ve Dünya Sağlık Örgütünün hadiseyi bir pandemi olarak ilan etmesiyle COVID-19'un turizm endüstrisine olan yansımaları küresel bir kimlik kazanmıştır. Böylece salgından kaynaklı olarak turizm ișletmeleri faaliyetlerini durdurmaya ve çalıșanları ișten çıkarmaya bașlamıștır. Turizmde iș kaybının dünya çapında yaklaşık 50 milyon kişi olacağ 1 tahmin edilmektedir (WTTC, 2020). Restoranlar başta olmak üzere çoğu turizm şirketi salgın sırasında çalışanlarını ücretsiz izine ayırma politikası izlemiştir (Lucas, 2020).

Farklı araştırmalarda pandeminin turizm endüstrisine olan yansımalarıyla ilgili farklı farklı senaryolar olmakla birlikte, en çarpıcı bilgiler Birleşmiş Milletler Dünya Turizm Örgütü’ne (UNWTO) aittir. Örgüt bu pandeminin uluslararası bir kriz olduğunu ve turizm endüstrisine olabilecek etkilerinin tespiti için erken olduğunu bildirmektedir. Ancak, pandemi nedeniyle ülkelerin sınırlarını kapatmaları ve havayolu hizmetlerinin işleyişini durdurmaları dikkate alındığında, COVID-19 nedeniyle uluslararası turist varışlarında \% 20 ile $\% 30$ oranında bir düşüşün ve turizm gelirlerinde ise toplam 300-450 milyar dolarlık bir zararın olabileceğini ön görmektedir (UNWTO, 2020). Uluslararası Hava Taşımacılığı Birliği (IATA) ise 2020 yılında yolcu gelirlerinde tahmini 113 milyar dolar zarar (\% 19) olacağını bildirmiștir (Pearce, 2020). Bu değerlendirmelerin dahi iyimser oldukları söylenebilir. Özellikle yaz mevsimindeki üç aylık dönemin tamamlanmasının ardından salgının turizmi nasıl etkileyeceğiyle ilgili daha sağlıklı değerlendirmelerin yapıllabileceği ifade edilebilir. 
COVID-19 küresel salgınının turizm endüstrisi ve alt sektörlerine olan somut etkilerinin yanında, endüstriye hakim genel felsefeyi de baştan sona dönüştürdüğü bir gerçektir. Pandemi insanın coğrafi mesafeler algısı ve bir topluluğa, bir ülkeye ve küresel veya yerel bir boyuta ait olma hissini yeniden tasarlamayı zorunlu kılmaktadır. Son on yıllarda başta turizmde olmak üzere dünya çapında yaşanılan yoğun hareketlik 2020 yılının ilk çeyreği itibariyle yerini birdenbire cevapsız sorulara ve yaygın bir belirsizlik hissine bırakarak aniden durma noktasına gelmiştir. COVID-19 küresel krizinin neden olduğu 'sıfırlama' sonrasında turizm ve misafirperverliğin yeniden oluşumu sanc1lı bir süreci gerektirecek gibi görünmektedir (Tomassini ve Cavagnaro, 2020).

Benjamin ve diğerleri (2020) pandemi sonrası turizm faaliyetleriyle ilgili bazı endişeleri dile getirmekte ve pandeminin turizmdeki bazı problemlerin yeniden gözden geçirilmesi ve çözüme kavuşturulması için bir firsat olarak değerlendirilmesi gerektiğini ifade etmektedir. Pandemiden sonra insanların istemsiz seyahat kararları, aşırı turizm kalıpları ve turizmin sosyal mesafeye bağımlı yapısının turizmde uygulanan yeni normal kurallarının bazı riskler içermesine neden olmaktadır. Araştırmacılar bunu Hong Kong'daki bir protestoda duvara yazılan bir sözle anlatmaktadır. "Normale dönemeyiz, çünkü sahip olduğumuz normal tam olarak problemdi". Turizm zaten tarih boyunca endüstrinin ve toplumlarının şimdi kendilerini bulduğu ikileme kısmen katkıda bulunan bir dizi sistemli eşitsizliği normalleştirmiştir. Sadece bir gereklilik olmasa bile, pandemi sonrası turizm sadece gelir elde etmek ve pazarda rekabet avantajı elde etmek için değil, aynı zamanda endüstriyi anlamlı yollarla düzenlemek ve iyileştirmek içinde bir fırsattır. Yeni normal, pandemi öncesi turizmde yaşanan kriz ve gerginlikleri ve eşitlikçi gündemin bütünsel ve bütünleşik doğasını açıkça kabul etmektedir. Bu noktada COVID-19 aşırı turizmden ciddi şekilde zarar gören destinasyonların kendilerini yenilemelerine imkan sağlamaktadır. Örneğin; pandemi Venedik için sembol haline gelen kanalların çevresel yenilenmelerine, kirlilik ve atıklardan arındırılmasına yardımcı olmuştur (Clifford, 2020)

"Sosyal mesafe" vurgusuyla başlayan COVID-19 sonrası yaşam biçiminin getirdiği sayısız kısıtlama ile insanlar daha fazla doğaya geri dönmeyi tercih etmekte, yavaşlamak için zaman kazanmakta ve uluslararası seyahat kısıtlamaları ile daha fazla yurt içi seyahatlerle ilgilenmeye başlamaktadır. Pandemi sonrası insanlar tekrar turizm faaliyetlerine katılacak, ancak bu faaliyetlerde tercihler "Sosyal mesafeye" daha uygun tercihlerde yoğunlaşacak gibi görünmektedir. Bu kapsamda "yavaş turizm" denilen olgunun tercih edilebilir bir tatil tercihi olarak ön plana çıkacağı düşünülmektedir (Travelzoo, 2020; Benjamin ve diğerleri, 2020).

\section{COVID-19'un Kamp ve Karavan Turizmine Olası Yansımaları}

Kentleşme olgusuyla beraber birçok faktörün etkisiyle doğaya dayalı turizm türlerine ilgi günden güne artış göstermektedir. Bunlardan birisi de kamp ve karavan turizmidir. Antik Yunan'a dayanan kökeniyle beraber bilinen en eski açık hava rekreasyon faaliyeti (Birdir ve diğerleri, 2015: 168) olan kampçılık faaliyetinin tatil anlamında ilk örnekleri 1800'lerin sonuna 1900'lerin başına denk gelmektedir (Topay ve Koçan, 2009:117). Kampçılık faaliyeti çadır, karavan vb. alternatif konaklama imkânlarıyla gerçekleştirilmekte ve çadır kurulmasına, karavanların park etmesine ve temel ihtiyaçların karşılanmasına imkân tanıyan bu alanlar 'kamping' olarak isimlendirilmektedir. Karavan konaklamaları da büyük oranda kamping alanlarında gerçekleştirildiği için doğaya dayalı bir turizm türü olarak 'kamp ve karavan' turizmi şeklinde değerlendirilmektedir.

COVID-19 pandemisine bağlı olarak turist tercihlerinde değişiklikler olacağı düşünülmekte ve bu konu da araştırmalar süregelmektedir. Türkiye Cumhuriyeti Kültür ve Turizm Bakanlığ tarafından COVID-19 pandemisi göz önünde bulundurularak turizm sektörü için dört ana başl1kta 132 tedbir kriteri belirlenmiştir. Bu kriterler insan sağlı̆̆ için önemli ve gerekli olmakla birlikte rahatlama motivasyonu ön planda olan turistler tarafindan abartılı karşılanabilir. İşte bu noktada kamp ve özellikle de "özgürlüğü" sembolize etmesi bakımından hareketli bir konaklama aracı olarak karavanların (Ellis, 2010; Brooker ve Joppe, 2013:1; Smithson ve Smithson, 1970: 117'den 
akt. Doğantan, 2014: 24) değişen tercihlerde öne çıkacağ 1 ve "evini sırtında taşıyan salyangozlar" (Lashley, 2015:115) benzetmesiyle açıklanan karavancıların sayısında artış olacağı düşünülmektedir. Pandemi durumuna bağlı olarak kamp ve karavan turizmine katılımın artacağını düşündürücü bir faktör de sağlık endişesidir. Her ne kadar çok büyük alanlara kurulu konaklama işletmeleri bulunsa da, kamping alanlarında tedbir amaçlı sosyal mesafenin rahat sağlanacağı ve bulaş riskinden uzak kalınmasının daha kolay olacağ 1 düşünülebilir. Bu açıdan kamp ve karavan turizmi "izole tatil" (Yalçın, 2020) arayışı olanların tercihleri arasında yer edinebilir. Öyle ki, pandemi durumuna bağlı olarak kamp ve karavan turizmine yönelik talebin arttığ görsel basında birçok haber çıkmıştır. Tablo 1'de 1 Mayıs 2020 tarihinden itibaren çıkan haberlerden bazı örneklere yer verilmiştir.

Tablo 1. Kamp ve Karavan Turizmi Talebiyle İlgili Haberler

\begin{tabular}{|c|c|c|}
\hline Haber tarihi & Haber yazari/yeri & Haber başlığı \\
\hline 01.05 .2020 & Birgün & $\begin{array}{c}\begin{array}{c}\text { Koronavirüs salgınından sonra karavan siparişleri yüzde } 300 \\
\text { arttı }\end{array} \\
\end{array}$ \\
\hline 01.05 .2020 & Dimtv & $\begin{array}{l}\text { OTELCILLERİ ÜZEN HABER! Yeni normaller ‘Karavan’ } \\
\text { talebini arttırdı }\end{array}$ \\
\hline 05.05 .2020 & Oktar & Corona Virüs salgınından sonra küçük karavanlara talep arttı \\
\hline 07.05 .2020 & Yarımbatman ve Özev & Koronavirüsten sonra kamp çadırına talep arttı \\
\hline 11.05 .2020 & Haber7 & $\begin{array}{c}\text { Çadır tatilciliği bu yıl artıyor! Çadır alırken nelere dikkat } \\
\text { edilmeli? }\end{array}$ \\
\hline 13.05 .2020 & Takvim & $\begin{array}{c}\text { Koronavirüs sürecinde karavanlara yurt içi ve yurt dışından } \\
\text { talep arttı }\end{array}$ \\
\hline 20.05 .2020 & Cnntürk & $\begin{array}{c}\text { Koronavirüsten uzak doğayla iç içe tatil! Kamp, karavan ve } \\
\text { bungalov tesislerine talep arttı }\end{array}$ \\
\hline 26.05 .2020 & Şan & Salgında karavan tatiline talep arttı \\
\hline 03.06 .2020 & Habertürk & Korona günlerine "karavan tatili" damgasını vuruyor \\
\hline 03.06 .2020 & Birgün & Salgın tatil kültürümüzü değiştirdi \\
\hline
\end{tabular}

Pandemi sonrası normalleşme sürecinde konaklama işletmelerinin; sezonu geç açmalarından, tam kapasite çalışamayacak olmalarından ve tedbirler kaynaklı maliyet kalemlerindeki artışlardan dolayı normalin üzerinde fiyat uygulamalarına gideceği öngörülebilir. Türkiye Seyahat Acenteleri Birliği bu yönde görüş bildirmiş ve insanların bu yıl daha alternatif tatilleri tercih edecekleri, butik otel ve pansiyonların daha çok tercih edileceği, bir ailenin küçük bir pansiyonu dahi kapatabileceği gibi öngörüler sunmuştur. Buna rağmen otellerin tam kapasite çalışmama ihtimallerine göre fiyatların eskiye oranla daha yüksek olabileceği ifade edilmektedir (https://www.turizmguncel.com/haber/acik-bufeler-kalkacak-maske-zorunlu-olacak,

ifadelerini kurmuştur. Dolayısıyla mevcut durumlar dahilinde talebe bağlı olarak karavan fiyatlarında artış yaşanmakla beraber, kamp alanlarındaki çadır konaklamalarının normal konaklama işletmelerine göre ucuz olması da tercih için cezbedici bir faktör olarak değerlendirilebilir. Brooker ve Joppe (2013:1) lüks olanaklarla kamp hizmeti sunan glamping tesislerine kadar farklı segmentlerde değerlendirdiği kamp konaklamasını düşük maliyetli bir turizm nişi olarak açıklamıştır. Öyle ki Şalk ve diğerleri (2018: 138) yaptıkları araştırmada çadırlı kamp faaliyetine katılma motivasyonları arasında 'fiyatın uygun oluşu' bulunmaktadır. İngiltere merkezli faaliyetlerini sürdüren bir pazar araştırma firmasının raporunda da, artan işsizlik ve ekonomik gerileme zamanlarında kamp ve karavan turizmine yönelimin arttığı vurgulanmıştır (Mintel, 2013).

Gürsoy ve Chen'in (2012:673) yaptıkları araştırmada, kamp yapmayanların da kamp etkinliğine olumlu bir bakış açısı olmasına rağmen itici bir gücün yoksunluğunu yaşadıkları sonucuna ulaşılmışırı. COVID-19 salgını küresel anlamda bir olumsuzluğun tezahür etmesi 
şeklinde kabul edilir iken, kamp ve karavan turizmi talebi adına zorunluluktan doğan bir itici güç olarak değerlendirilebilir. İnsanlar sağlık endişelerinin yanında yaşadıkları zor sürecin etkisiyle de tercihlerini bu yöne çevirebilirler. Kamp ve karavan turizminin temel motivasyonlarından olan "kaçış duygusu" (Brooker ve Joppe, 2014: 336) ve "psikolojik rahatlama isteği" (Brooker ve Joppe, 2013: 3), mevcut şartlar altında gerçek manada kendisini gösterebilir. Nihai olarak güvenilir ve rahat bir tatil aktivitesi algısıyla beraber otel fiyatlarındaki artış karşısında kamp alanları için "uygun fiyatlı konaklama imkânı" konumlaması (Jurdana ve diğerleri, 2009:178) potansiyel talebi efektif talebe dönüştürebilir.

\section{Sonuç ve Tartışma}

Bütün dünyayı etkisi altına alan COVID-19, toplumları farklı açılardan etkilemektedir. İlk olarak makro anlamda ülkeleri, mikro anlamda ise firmaları ve bireyleri ekonomik, sosyal ve psikolojik anlamda etkilemiştir. Aslında birbirine bağlı olan bu unsurların her biri bu pandemi sürecinden olumsuz etkilenmiştir. Böylece COVID-19'un olumsuz etkileri farklı ekonomik birimlerin karşı1ıklı etkileşimleriyle daha da artmıştır. Nitekim turizm temalı kentler bu pandemi sürecinde birer hayalet kente dönüşmüştür (Haywood, 2020). Sosyal mesafe sloganı ile COVID-19 salgınının turizm endüstrisindeki etkilerinin azaltılması ve bu hayalet kentlerin turizm ile yeniden canlandırılması hedeflenmektedir. Peki, turizmde sosyal mesafe mümkün mü?

Samimi ve sıcak insan ilişkilerine dayanan turizm faaliyetleri COVID-19 pandemisi nedeniyle farklı bir kimlik kazanacak gibi durmaktadır. Zira pandeminin turistler üzerinde oluşturduğu olumsuz psikolojik etkiler, turistleri salgından etkilenmeden turistik faaliyetler yapabilecekleri alternatif talep ve arz kaynaklarına yönlendirmiştir. Arz bakımından özellikle doğa temelli alternatif turizm türlerine bir yönelimin olacağı tahmin edilmektedir. Özellikle sakin ve dinleme imkânı sağlayan yayla turizmi, çiftlik turizmi, kamp turizmi, karavan turizm vb. doğa ile uyumlu turizm çeşitlerine bir yönelimin olacağı düşünülmektedir. Zhu ve Deng (2020) yaptıkları ampirik araştırmada Çinlilerin doğa temelli turizmi tercih ettiklerini tespit etmişlerdir. Araştırmada insanların riskten kaçınmak için kırsal turizmi tercih ettikleri vurgulanmaktadır. Bu nedenle kırsal bölgelerde salgına ilişkin önlemlerin alınması gerektiğini ifade etmektedir. Bunun yanında kalabalık şehirlerde yapılan kültür turları, kumar turizmi gibi insan etkileşiminin yoğun olduğu turizm çeşitleri (Wong, 2020) ile kalabalık ortamlarda gerçekleşen alışveriş turizminin pandemiden olumsuz etkileneceği düşünülmektedir. Deniz, kum ve güneş merkezli kitle turizmiyle ilgili de ciddi endişeler söz konusudur. Çünkü virüsün deniz veya havuz sularılya bulaşma riskine dair değerlendirmeler olmakla birlikte, kesinleşmiş araştırmalar söz konusu değildir. Plajlarda "sosyal mesafe" kurallarıyla ilgili birtakım çalışmalar olsa da dünyadaki farklı plajlardan gözlemlendiği kadarıyla bunda başarı sağlamakla ilgili bazı risklerin olduğunu ifade etmek gerekmektedir.

Turizm talebinin pandemi nedeniyle normalden farklı reaksiyon göstereceği bir diğer önemli husus konaklama tercihidir. Çünkü konaklama esnasında büyük kalabalıkların uzun süre aynı ortamda kalmaları gerekmektedir. Özellikle otel, tatil köyü ve tatil kompleksi gibi büyük konaklama işletmelerinde "sosyal mesafe" kurallarının uygulanabilirliğiyle ilgili ciddi endişeler mevcuttur. Bu anlamda tatil bölgelerindeki her şey dahil sistemle çalışan konaklama tesislerinde risk daha da yüksektir. Çünkü bu tür tesislerde bütün öğünler için yemekler ortak olmakta ve açık büfeler yardımıyla hizmet verilmektedir. Bu durum özellikle hijyen ve mesafe ile ilgili büyük riskler ortaya çıkarabilir. Bu konseptin değiştirilmesi talep edilebilirlikle ilgili sorunlar ortaya çıkarabilmektedir. Zira turistler bu konsepti bütün hizmetleri bir paket halinde uygun fiyatlardan satın aldığ için tercih etmektedir. Bunun yerine pansiyon, kamp, karavan, villa vb. konaklama tercihlerinde önemli bir talep artışının olduğu ve ilerde bir süre de durumun bu şekilde devam edeceği söylenebilir.

Arz ve talep perspektifiyle bakıldığında, COVID-19 sürecinden sonra kamp ve karavan turizminin "sosyal mesafe" kurallarına uygun olması nedeniyle tercih edilecek bir alternatif turizm çeşidi ve konaklama tipi olarak ön plana çıkacağı düşünülmektedir. Bu turizm ve konaklama çeşidi 
sosyal mesafenin en önemli unsurlarından biri olan fiziksel mesafeyi (McCartney, 2020) ayarlamak için önemli firsatlar içermektedir. Ayrıca, başta yiyecek-içecek hizmetleri olmak üzere temel ihtiyaçlar direk turistler tarafından karşılanmaktadır. Böylece bu konaklama tipinde risk azalmakta, güven duygusu gelişmekte ve psikolojik rahatlama sağlanmaktadır (Brooker ve Joppe, 2013). Süreçte karavan satışlarıyla ilgili gelişmeler ve kamp alanlarının uygulamaları ve hazırlıkları da bu durumu destekler niteliktedir.

$\mathrm{Bu}$ araştırmanın en önemli kısıtı çalışmanın kavramsal bir incelmeye dayanmasıdır. Zira konuya ilişkin ampirik çalışmaların yapılabilmesi için yaz mevsimindeki gelişmelerin seyrine bakmak yararlı olabilir. Gerçekleşmiş talebe göre ileriki zamanlarda alternatif turizm ve konaklama tercihleri bağlamında turist davranışlarını ölçen uygulamalı araştırmalar gerçekleştirilebilir.

\section{Kaynakça}

Backer, J. A., Klinkenberg, D., \& Wallinga, J. (2020). Incubation period of 2019 novel coronavirus (2019-nCoV) infections among travellers from Wuhan, China, 20-28 January 2020. Eurosurveillance,25(5), https://dx.doi.org/10.2807\%2F1560-7917.ES.2020.25.5.2000062

Baker, T. (2020, May 10). Chinese hotels seeing steep declines from coronavirus. http://hotelnewsnow.com/Articles/300132/Chinese-hotels-seeing-steepdeclines-fromcoronavirus.

Benjamin, S., Dillette, A., \& Alderman, D. H. (2020). "We can't return to normal": committing to tourism equity in the post-pandemic age. Tourism Geographies, Special Issue, 1-8. https://doi.org/10.1080/14616688.2020.1759130

Birdir, K., Unur, K., \& Dalgıç, A. (2015). Türkiye ve dünya'da kamping ve yeni bir turistik ürün olarak 'glamping'. 1. Avrasya Uluslararası Turizm Kongresi Güncel Konular, Eğilimler ve Göstergeler Bildiriler Kitabl-2, 168-177.

Birgün. (2020, Mayıs 20). Salgın tatil kültürümüzü değiştirdi. https://www.birgun.net/haber/salgintatil-kulturumuzu-degistirdi-303197

Birgün.net. (2020, Mayıs 20). Koronavirüs salgınından sonra karavan siparişleri yüzde 300 arttı. https://www.birgun.net/haber/koronavirus-salginindan-sonra-karavan-siparisleri-yuzde300-artti-299068.

Brooker, E., \& Joppe, M. (2013). Trends in camping and outdoor hospitality-An international review. Journal of Outdoor Recreation and Tourism, 3(4), 1-6. https://doi.org/10.1016/j.jort.2013.04.005

Brooker, E., \& Joppe, M. (2014). A critical review of camping research and direction for future studies. Journal of Vacation Marketing, 20(4), 335-351. https://doi.org/10.1177/1356766714532464

Buhalis, D., \& Law, R. (2008). Progress in information technology and tourism management: 20 years on and 10 years after the internet-the state of eTourism research. Tourism Management, 29(4), 609-623. https://doi.org/10.1016/j.tourman.2008.01.005

Chen, L., \& Evans, T. (2004). Human resources for health: overcoming the crisis. The Lancet, 364(9449), 1984-1990.

Chu, D. K., Pan, Y., Cheng, S., Hui, K. P., Krishnan, P., Liu, Y., Daisy, Y. M. NG., Carrie, K. C. W., Peng, Y., Quanyi, W., Peiris, M., \& Poon, L. L. M. (2020). Molecular diagnosis of a novel coronavirus (2019-nCoV) causing an outbreak of pneumonia. Clinical Chemistry 66(4), 549-555. https://doi.org/10.1093/clinchem/hvaa029 
Clifford, C. (2020, March 18). The water in Venice, Italy's canals is running clear amid the COVID-19 lockdown. CNBC. https://www.cnbc.com/2020/03/18/photos-water-invenice-italys-canals-clearamid-covid-19-lockdown.html.

Cnntürk. (2020, Mayıs 25). Koronavirüsten uzak doğayla iç içe tatil! Kamp, karavan ve bungalov tesislerine talep artt1. https://www.cnnturk.com/seyahat/koronavirusten-uzak-dogayla-icice-tatil-kamp-karavan-ve-bungalov-tesislerine-talep-artti?page $=1$.

Del Chiappa, G., \& Baggio, R. (2015). Knowledge transfer in smart tourism destinations: analyzing the effects of a network structure. Journal of Destination Marketing \& Management, 4(3), 145-150. https://doi.org/10.1016/j.jdmm.2015.02.001

Dimtv. (2020, May1s 25). Otelcileri Üzen Haber! Yeni normaller 'Karavan' talebini arttırdı. https://dimtv.tv/2020/otelcileri-uzen-haber-yeni-normaller-karavan-talebini-arttirdihaberler/31210/.

Doğantan, E. (2014). Frigya bölgesine alternatif konaklama tesisi önerisi: karavancilık. (Yayımlanmamış Yüksek Lisans Tezi). Anadolu Üniversitesi Sosyal Bilimler Enstitüsü, Eskişehir.

Ellis, S. (2010, June 2). Camping and caravanning: why so popular and is it sustainable? Tourism Insights. https://www.cabdirect.org/cabdirect/abstract/ 20103311194.

Erol, M. (2010). Ekonomik kriz ve kobiler. Journal of Entrepreneurship and Development. 5(1), $165-181$.

Fahimi, A., Saint Akadiri, S., Seraj, M., \& Akadiri, A. C. (2018). Testing the role of tourism and human capital development in economic growth: a panel causality study of micro states. Tourism management perspectives, 28, 62-70. https://doi.org/10.1016/j.tmp.2018.08.004

Gamble, P. R. (1992). The educational challenge for hospitality and tourism studies. Tourism Management, 13(1), 6-10. https://doi.org/10.1016/0261-5177(92)90023-Z

Gills, B. K. (2008). The swinging of the pendulum: the global crisis and beyond. Globalizations, 5, 513-522. https://doi.org/10.1080/14747730802567389

Gralinski, L. E., \& Menachery, V. D. (2020). Return of the coronavirus: 2019-nCoV", Viruses, 12(2), 135. https://doi.org/10.3390/v12020135

Gürsoy, D., \& Chen, B. T. (2012). Factors influencing camping behavior: the case of Taiwan. Journal of Hospitality Marketing \& Management, 21(6), 659-678. https://doi.org/10.1080/19368623.2012.627239

Haber7. (2020, Mayıs 20). Çadır tatilciliği bu yıl artıyor! Çadır alırken nelere dikkat edilmeli? https://www.haber7.com/seyahat/haber/2972830-cadir-tatilciligi-bu-yil-artiyorcadiralirken-nelere-dikkat-edilmeli/?detay $=2$.

Habertürk. (2020, Mayıs 20). Korona günlerine "karavan tatili" damgasını vuruyor. https://www.haberturk.com/korona-gunlerine-karavan-tatili-damgasini-vuruyor-2700136.

Hall, C. M. (2010). Crisis events in tourism: subjects of crisis in tourism. Current issues in Tourism, 13(5), 401-417. https://doi.org/10.1080/13683500.2010.491900

Hall, C. M., \& O'Sullivan V. (1996). Tourism, political stability and violence. A. Pizam \& Y. Mansfeld (Eds.), Crime, Tourism and Secuirty Issues (pp. 105-123). Wiley.

Hall, C. M., Timothy, D., \& Duval, D. (2003). Security and tourism: towards a new understanding?" Journal of Travel and Tourism Marketing, 15(3), 1-18. https://doi.org/10.1300/J073v15n02_01 
Haque, T. H., \& Haque, O. (2018). The swine flu and its impacts on tourism in Brunei. Journal of Hospitality and Tourism Management, 36, 92-101. https://doi.org/10.1016/j.jhtm.2016.12.003

Haywood, K. M. (2020). A post-COVID future: tourism community re-imagined and enabled. Tourism Geographies, 599-609. https://doi.org/10.1080/14616688.2020.1762120

Jurdana, D. S., Milohnic, I., \& Cvelic - Bonifacic, J. (2009). The features of the naturist camping market. Tourism and Hospitality Management, 15(2), 177-192.

Kongoley, P. S. (2015). The impact of ebola on the tourism and hospitality industry in Sierra Leone. International Journal of Scientific and Research Publications, 5(12), 542-550.

Kuo, H. I., Chen, C. C., Tseng, W. C., Ju, L. F., \& Huang, B. W. (2008). Assessing impacts of SARS and Avian Flu on international tourism demand to Asia. Tourism Management, 29(5), 917-928. https://doi.org/10.1016/j.tourman.2007.10.006

Lashley, C. (2015). Researching snails on holiday: an agenda for caravanning and caravanners? Research in Hospitality Management, 5(2), 115-122. https://doi.org/10.1080/22243534.2015.11828336

Lee, Y. F., \& Harrald, J. R. (1999). Critical issue for business areaimpact analysis in business crisis management: Analytical cap-ability. Disaster Prevention and Management, 8(3), 184189. https://doi.org/10.1108/09653569910275382

Lickorish, L.Carson, J., \& Jenkins, L. (1997). An introduction to tourism. Heinemann

Lucas, A. (2020, March 19). Olive Garden's parent begins offering paid sick leave to all employees amid coronavirus outbreak. CNBC. https://www.cnbc.com/2020/03/19/dardenrestaurants-driq3-2020-earnings-beat-estimates.html.

McAleer, M., Huang, B., Kuo, H., Chen, C. \& Chang, C. (2010). An econometric analysis of SARS and Avian flu on international tourist arrivals to Asia. Environmental Modelling \& Software, 25(1), 100-106. https://doi.org/10.1016/j.envsoft.2009.07.015

McCartney, G. (In Press). The impact of the coronavirus outbreak on Macao. From tourism lockdown to tourism recovery. Current Issues in Tourism, 1-10. https://doi.org/10.1080/13683500.2020.1762549

Menachery, V. D., Dinnon, K. H., Yount, B. L., McAnarney, E. T., Gralinski, L. E., Hale, A., ... \& Graham, B. (2020). Trypsin treatment unlocks barrier for zoonotic bat coronavirus infection. Journal of Virology, 94(5), 1-15. https://doi.org/10.1128/jvi.01774-19

Mintel. (2013). Camping and caravanning - UK, London: Mintel Group. https://reports.mintel.com/display/638029

Mizrachi, I. \& Fuchs, G. (2016). Should we cancel? An examination of risk handling in travel social media before visiting ebola-free destinations. Journal of Hospitality and Tourism Management, 28, 59-65. https://doi.org/10.1016/j.jhtm.2016.01.009

Munster, V. J., Koopmans, M., van Doremalen, N., van Riel, D. \& de Wit, E. (2020). A Novel Coronavirus Emerging in China-Key Questions for Impact Assessment. New England Journal of Medicine, 382(8), 692-694. https://doi.org/10.1056/NEJMp.2000929

Oktar, R. K. (2020, Mayıs 5). Corona virüs salgınından sonra küçük karavanlara talep arttı. Hürriyet. https://www.hurriyet.com.tr/gundem/kucuk-karavanlara-talep-artti-41509940 
Page, S., Yeoman, I., Munro, C., Connell, J. \& Walker, L. (2006). A casestudy of best practice-visit Scotland's prepared response to aninfluenza pandemic. Tourism Management, 27(3), 361-393. https://doi.org/10.1016/j.tourman.2006.01.001

Pambudi, D., N. McCaughey. \& R. Smyth, R. (2009). Computable general equilibrium estimates of the impact of the bali bombing on the indonesian economy. Tourism Management, 30(2), 232-39. https://doi.org/10.1016/j.tourman.2008.06.007

Paraskevas, A., Altinay, L., McLean, J. \& Cooper, C. (2013). Crisis knowledge in tourism: Types, flows and governance. Annals of Tourism Research, 41, 130-152. https://doi.org/10.1016/j.annals.2012.12.005

Pearce, B. (2020). COVID-19 updated impact assessment. https://www.iata.org/en/iatarepository/publications /economicreports/coronavirus-updated-impact-assessment/

Perlman, S. (2020). Another decade, another coronavirus. The New England Journal of Medicine, 382, 760-762. https://doi.org/10.1056/nejme2001126

Pine, R. \& McKercher, B. (2004). The impact of SARS on Hong Kong's tourism industry. International Journal of Contemporary Hospitality Management, 16(2), 139-143. https://doi.org/10.1080/1094166042000330236

Raymond, C. \& Brown, G. (2007). A spatial method for assessing resident and visitor attitudes towards tourism growth and development. Journal of sustainable tourism, 15(5), 520540. https://doi.org/10.2167/jost681.0

Şalk, S., Dumanlı, Ş. \& Köroğlu, Ö. (2018). Tatilcilerin çadırlı kamp faaliyetlerine katılım motivasyonlarının belirlenmesi. Sosyal ve Beşeri Bilimler Dergisi, 10(2), 130-144.

Şan, C. (2020, Mayıs 26). Salgında karavan tatiline talep arttı. Anadolu Ajansı. https://www.aa.com.tr/tr/turkiye/salginda-karavan-tatiline-talep-artti/1853615

Scott, N. \& Laws, E. (2005). Tourism crises and disasters: Enchancing understanding of system effects. Journal of Travel \& Tourism Marketing, 19(3), 149-158. https://doi.org/10.1300/j073v19n02_12

Smith, V. L. (1998). War and tourism: An American ethnography. Annals of Tourism Research, 25(1), 202-227. https://doi.org/10.1016/S0160-7383(97)00086-8

Stylidis, D. \& Terzidou, M. (2014). Tourism and the economic crisis in Kavala, Greece. Annals of Tourism Research, 44, 210-226. https://doi.org/10.1016/j.annals.2013.10.004

Takvim. (2020, Mayıs 13). Koronavirüs sürecinde karavanlara yurt içi ve yurt dışından talep arttı. https://www.takvim.com.tr/ekonomi/2020/05/13/koronavirus-surecinde-karavanlara-yurtici-ve-yurt-disindan-talep-artti

Tang, C. F. \& Abosedra, S. (2014). Small sample evidence on the tourism-led growth hypothesis in Lebanon. Current Issues in Tourism, 17(3), 234-246. https://doi.org/10.1080/13683500.2012.732044

Thompson, A. (2011). Terrorism and tourism in developed versus developing countries. Tourism Economics, 17(3), 693-700. https://doi.org/10.5367/te.2011.0064

Tomassini, L. \& Cavagnaro, E. (2020). The novel spaces and power-geometries in tourism and hospitality after 2020 will belong to the 'local'. Tourism Geographies, Special Issue, 1-7. https://doi.org/10.1080/14616688.2020.1757747 
Topay, M. \& Koçan, N. (2009). Kamping/çadırlı kamp için alan seçim kriterlerinin belirlenmesi ve Bartın/Uluyayla'da örnek bir uygulama. Süleyman Demirel Üniversitesi Orman Fakültesi Dergisi, A(1), 116-128.

Travelzoo. (2020, March 11). Travelzoo U.S. Survey Reveals Flexible Travellers Find Opportunity in Current Crisis Climate. http://ir.travelzoo.com/news-releases/news-releasedetails/travelzoo-ussurvey-reveals-flexible-travelers-find-opportunity

Tse, T. S. M. (2006). Crisis management in tourism. In D. Buhalis ve C. Costa (Eds.), Tourism Management Dinamics, Trend, Management and Tolls (pp. 28-38). Elsevier.

Turizmgüncel. (2020, Nisan 25). Açık büfeler kalkacak, maske zorunlu olacak. https://www.turizmguncel.com/haber/acik-bufeler-kalkacak-maske-zorunlu-olacak

UNWTO (World Tourism Organization). (2019). International tourism highlights 2019 edition. https://www.e-unwto.org/doi/pdf/10.18111/9789284421152

UNWTO (World Tourism Organization). (2020a). Global and regional tourism performance. https://www.unwto.org/global-and-regional-tourism-performance

UNWTO (World Tourism Organization). (2020b). Tourism and coronavirus disease (COVID-19). www.unwto.org/tourismcovid-19-coronavirus

Walters, G., Mair, J. \& Lim, J. (2016). Sensationalist media reporting of disastrous events: Implications for tourism, Journal of Hospitality and Tourism Management, 28, 3-10. https://doi.org/10.1016/j.jhtm.2016.04.008

Wang, C., Horby, P. W., Hayden, F. G. \& Gao, G. F. (2020). A novel coronavirus outbreak of global health concern, The Lancet, 395(10223), 470-473. https://doi.org/10.1016/s01406736(20)30185-9

Wen, J., Kozak, M., Yang, S., \& Liu, F. (2020). COVID-19: potential effects on Chinese citizens' lifestyle and travel. Tourism Review, 1-14. https://doi.org/10.1108/tr-03-2020-0110

Wong, J. K. C. (2020, March 24). Macau Chief Executive says COVID-19 an "exam” for gaming concessionaires' CSR contribution. https://www.asgam.com/index.php/2020/03/24/macau-chief-executive-says-covid-19-anexam-for-gamingconcessionaires-csr-contribution/

WTTC (World Travel and Tourism Council). (2020). Only the G20 can drive forward a coordinated recovery response to the COVID-19 crisis says WTTC. https://wttc.org/News-Article/Only-the-G20-can-drive-forward-a-coordinated-recoveryresponse-to-the-COVID-19-crisis-says-WTTC

Yalçın, E. (2020, Mayıs 1). Yeni normalleşme sonrası kamp ve karavan turizmi. GM Turizm ve Yönetim Dergisi. https://www.gmdergi.com/guncel/yeni-normallesme-sonrasi-kamp-vekaravan-turizmi/

Yarımbatman, M. \& Özev, K. (2020, Mayıs 7). Koronavirüsten sonra kamp çadırına talep arttı. Hürriyet. https://www.hurriyet.com.tr/gundem/koronavirusten-sonra-kamp-cadirinatalep-artti-41511761

Zhu, H., \& Deng, F. (2020). How to influence rural tourism intention by risk knowledge during COVID-19 containment in China: Mediating role of risk perception and attitude. International Journal of Environmental Research and Public Health, 17(10), 3514. https://doi.org/10.3390/ijerph17103514 